\title{
ASSOCIATION OF COMBINED SETTING SETTING OPERATIONS
}

\author{
AN Khudoyarov - professor, DA Abdullaev - Associate Professor and MA Yuldasheva \\ Andijan branch of Tashkent State Agrarian University, Republic of Uzbekistan
}

\author{
http://doi.org/10.35410/IJAEB.2019.4472
}

\begin{abstract}
The article summarizes the results of the research on the basic parameters of drum aggregation for combining the preparation of forest plantations for planting. Combined aggregate bulk milling milling drum blade cutting blades with the required degree of fragmentation was mainly determined by milling drum rotation velocity and flour radius.
\end{abstract}

Keywords: Forestry plantations, combine units, turner crusher, milling drum, rotary velocity, blade, milling radius.

\section{INTRODUCTION}

No special units were used to prepare the forest plantations. There is no need to use existing aggregates or customized versions for men. And this will save energy and increase operating costs.

The latest research and research is a deliberate combination of integrating technological processes into the development of men's seedlings in order to provide rare flowers and medicinal plantations in forest plantations.

The combine unit is fitted with a flexible saw blade, a rudder cutter, a riveting grinding wheel for the rear wheels and a rear-wheel drive. Editing gear and flour mills, paddle rollers and aggregates made up of tractors designed for the tractor [1,2].

The results of the study of the combinator aggregate milling mills based on the basic parameters of drumming parameters.

Number of knives mounted on the drum. Combination unit cutter milling drum knife mounted double disk drive. The blades are mounted in the opposite of a single shot. It is advisable to have 2 to 4 knife blades per disk [3]. Plenty of knives, ie 4 drives, allow the drill to work much more smoothly and at higher speeds and thus yield better performance. We receive 4 times the number of knives that are mounted on each disc and 8 times the blades mounted on the drum.

Clarify the radius of expression of the radius of the drum [4] 


$$
R \geq R_{\partial}+\Delta h+h,
$$

bundle Rd - drum blade fastening locking knife radius, $\mathrm{m}$;

$\mathrm{h}$ - the knives are fastened with a hard disk and a steep slope trench, $\mathrm{m}$.

Drum knives are fastened with discus radius and valingine radius, number of blades, and elongation of the elongation of the elbow can be precisely specified.

$$
R_{\partial}=R_{\text {s }}+\frac{z b_{y}}{2 \pi},
$$

bund Rv - Frame drum milling radius, m;

z-Frame drum bit with number of knives on disk; cloves;

by - knife stacking crest, $\mathrm{m}$.

(2) when computing the statement (1) the expression is reproduced

$$
R \geq R_{\theta}+\frac{z b_{y}}{2 \pi}+\Delta h+h .
$$

$\mathrm{Rv}=25 \mathrm{~mm}, \mathrm{z}=4$, by $=50 \mathrm{~mm},=\mathrm{h}=20 \mathrm{~mm} \mathrm{[5]} \mathrm{and} \mathrm{h}=10 \mathrm{~cm}$. We accept the result of the yellows, $R=20 \mathrm{~cm}$.

Researching the process of milling milling drum blade cutting blades

The combination unit works on autumn plowed fields and spring-plowed fields. That is why the milling drum blades break down due to the damage caused by the toxicity of the fragments that have already occurred in the process. Conditions must be met in order for effective fragmentation of fragments [4]

$$
V_{y} \geq V_{\kappa p},
$$

bpm $\mathrm{Vy}$ - velocity of drum blade cutting into pieces, $\mathrm{m} / \mathrm{s}$; 
Vkr - grinding of drum cutter pieces

Supply Critical Impact Speed, m / s.

Definition [3]

$$
V_{\kappa p}=\left[\sigma_{u}\right] \sqrt{\frac{\left(J+m R^{2}\right)}{3 E J \rho\left(1-k^{2}\right)}},
$$

Ndre [three] settlement we seek effect Austin Cross-Border Cost, Pa;

$\mathrm{J}$ - moment of inertia of milling drum, kgm2;

$\mathrm{m}$ - mass of mass in $\mathrm{kg}$;

SAW - cross-section density, $\mathrm{kg} / \mathrm{m} 3$;

$\mathrm{k}$ - Ratio of Rectangular Recovery;

E soil elastic modules, Pa.

(4) expression analysis It also shows that the rate of criticism of the milling drum blades in the crosshairs depends on its parameters $(\mathrm{J}, \mathrm{R})$ and the mass and physicist properties of mechanical particles (m, [three], E, SAW, and k).

The pieces are crushed at the expense of helicopter seekers, as measured by milling drum knives. The scheme will be unpredictable at the output 1 to determine the speed of hitting helicopters to the cuts of the official knife

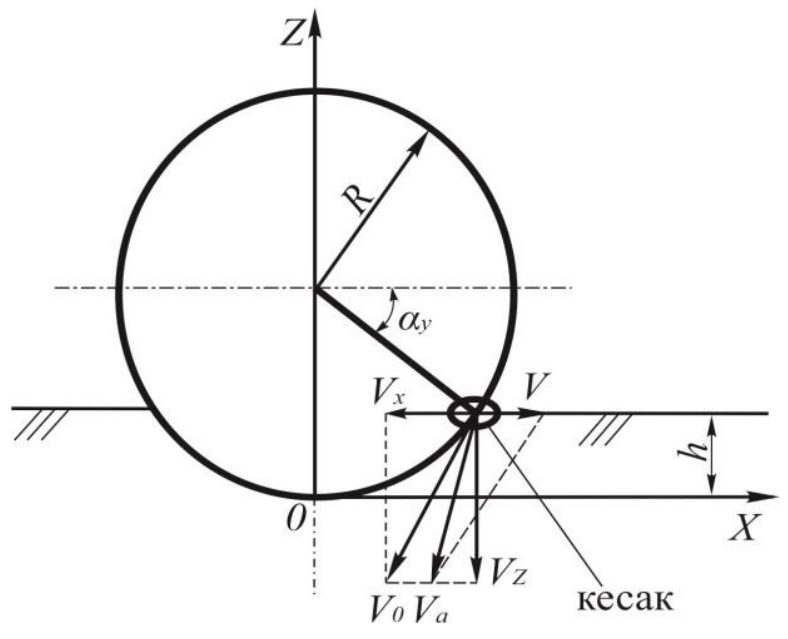

Picture 1 Schematic diagram of tracing grinding of drum blades 


$$
V_{y}=V_{z}=V_{0} \cos \alpha_{y}=V_{0} \cdot \frac{\sqrt{2 R h-h^{2}}}{R},
$$

Indre $\square \mathrm{u}$ - beans and degrees by turning the milling drum into pieces;

$\mathrm{h}$ - Processing depth of milling drum, $\mathrm{m}$.

(5) Expression analysis expiry Observe that Losey, and (3) the fulfillment of the terms and Demas request is obtained by correcting the speed of the Assos milling Drum Circle shredded at the intersection level.

Determine the circuit speed of the drum blades using the expressions (4) and (5). partridge in Assos

$$
V_{o} \frac{\sqrt{2 R h-h^{2}}}{R} \geq\left[\sigma_{u}\right] \sqrt{\frac{\left(J+m R^{2}\right)}{3 E J \rho\left(1-k^{2}\right)}}
$$

Needed decoration. From the bun

$$
V_{o} \geq\left[\sigma_{u}\right] R \sqrt{\frac{\left(J+m R^{2}\right)}{3 E J \rho\left(1-k^{2}\right)\left(2 R h-h^{2}\right)}} .
$$

Eco-friendliness.

(6) The expressiveness of the expression, the rotational speed of the drum blades depends on the инг radius, the momentum of inertia, the depth of processing and the coefficients of elasticity, mass, elastic modulus, density, and recovery.

Based on the studies done, $[\square]=3.5 \square 105 \mathrm{~Pa}, \mathrm{E}=1,9 \square 106 \mathrm{~Pa}, \square=1200 \mathrm{~kg} / \mathrm{m} 3, \mathrm{~m}=1.02 \mathrm{~kg}$, $\mathrm{k}=0.3$ [6,7], Acceptance of $\mathrm{J}=0.11 \mathrm{kgm} 2$ and $\mathrm{R}=0.2 \mathrm{~m},(6)$, the calculations obtained showed that the drum cutter drum rotation speed should be $6 \mathrm{~m} / \mathrm{s}$ to ensure high quality grinding. Considering that the torque required for the milling drum drifting has been achieved, it is advisable to accept the knife blade $6-7 \mathrm{~m} / \mathrm{s}$. 


\section{CONCLUSION}

The combined unit is divided into two drum kits, which are mounted on the drum blade unit, and the blades mounted on each disk receive 4 times the number of blades mounted on the drum.

Grinding mills drum blades are required to break the blades in order to maximize their grinding frequency.

The calculations showed that the drum section cuts the required radius of $20 \mathrm{~cm}$.

The results of the study showed that to ensure high quality milling, the milling drum cutter should reduce the rotational speed by $6 \mathrm{~m} / \mathrm{s}$.

\section{REFERENCES}

1. Khudoyberdiev TS, Khudoyorov AN, Yuldashev MA, IA Nazirzhonov, D. Khudoynazarov An international conference on the topic: "Current state of forestry plantation development and new technologies, which will be proposed for development". B.4-9.

2. Khudoyorov AN Combined aggregate for the minimum load // Technique in the cellar. Moscow, 2009. - No. 6. - p.56-57.

3.Synekov GN, Paeyov IM Theory and calculations machine. -M .: Machine Building, 1977. 328 p.

4. Dzhuraev AD, Tukhakuzuziev A., Mukhamedov J., Turdaliev V. The combination of the second and the second generation of vegetable seeds. Monograph. - Tashkent: Science and Technology, 2016, -180 p.

5. Kanarev FM Rotational Mail Machines and Orudy. -M .: Machine Building, 1983, -142 p.

6. Sadykov R.O. Rotation modes and parameters rotary rotation with vertical oscillations. Dissertation. technique. no. - Yangulyul, 2000. -110 p.

7.Abdurahmonov U.N. Parameters for audio traverses for propagated tractors // Author's abstract disk. blood tech nauk.- Yangiyul, 1996. - 16 p. 